\title{
Pengaruh Dukungan Organisasi, Budaya Organisasi Terhadap Employee Engagement Yang Berimplementasi Pada Loyalitas (Studi Kasus Pada BPR Arto Moro Semarang)
}

Muryanto Agus Nuswantoro

$\underline{\text { S1 Manajemen FE, Universitas Semarang, Semarang, Indonesia }}$

\section{INFO ARTIKEL}

Proses Artikel

Dikirim :

Diterima:

Dipublikasikan:

\begin{abstract}
ABSTRAK
Penelitian ini dilatarbelakangi oleh tingkat kedisiplinan karyawan BPR Arto Moro Semarang belum berada dalam tataran optimal. Tujuan penelitian ini adalah untuk menganalisis pengaruh dukungan organisasi, budaya organisasi terhadap employee engagement yang berimplementasi pada loyalitas kerjadi BPR Arto Moro Semarang. Jumlah sampel dalam penelitian ini 102 responden, menggunakan teknik sensus dimana seluruh karyawan 102 diambil sebagai sampel penelitian. Analisis yang digunakan dalam penelitian ini adalah analisis regresi linier berganda. Hasil penelitian diperoleh : pengaruh positif dan signifikan antara dukungan organisasi terhadap Employee Engagement karyawan, pengaruh positif dan signifikan antara budaya organisasi terhadap Employee Engagement karyawan, pengaruh positif dan signifikan antara dukungan organisasi terhadap loyalitas kerja karyawan, pengaruh positif dan signifikan antara budaya organisasi terhadap loyalitas kerja karyawan, pengaruh positif dan signifikan antara Employee Engagement terhadap loyalitas kerja karyawan. Koefisien determinasi $\left(\mathrm{R}^{2}\right)$ sebesar 0,63 yang berarti dukungan organisasi, budaya organisasi dan Employee Engagement berpengaruh sebesar 63\% terhadap loyalitas kerja karyawan, sedangkan sisanya $37 \%$ dipengaruhi oleh faktor yang lain.
\end{abstract}

Kata Kunci : (TNR 9)

Dukungan organisasi, budaya organisasi, Employee Engagement, loyalitas kerja..

\section{PENDAHULUAN}

Pengelolaan Sumber Daya Manusia di suatu perusahaan merupakan suatu keharusan jika perusahaan ingin maju dan berkembang, karena Sumber Daya Manusia merupakan asset penting agar perusahaan mampu bersaing dengan perusahaan lain. Menghadapi situasi dan kondisi tersebut, perusahaan harus menentukan strategi dan kebijakan manajemennya khususnya dalam bidang Sumber Daya Manusia ( SDM ). Oleh karena itu kebutuhan dan keinginan dari karyawan sebagai SDM juga harus didukung oleh pengelola perusahaan agar dapat berkomitmen dengan baik dan termotivasi atas apa yang dikerjakan dengan maksud untuk memuaskan karyawan supaya bekerja dengan hasil baik. 
Pola perilaku yang melekat secara keseluruhan pada diri setiap karyawan dalam sebuah perusahaan merupakan budaya kerja di perusahaan. Sehingga membangun budaya berarti juga meningkatkan dan mempertahankan sisi-sisi positif, serta berupaya membiasakan (habituating process) pola perilaku tertentu agar tercipta suatu bentuk baru yang lebih baik dalam rangka pelaksanaan pekerjaan untuk mencapai tujuan.

Sikap yang timbul sebagai akibat keinginan untuk setia dan berbakti baik itu pada pekerjaannya, kelompok, atasan maupun pada perusahaan tempatnya bekerja adalah bentuk loyalitas kerja karyawan, hal ini dapat menyebabkan seseorang rela berkorban demi memuaskan pihak lain atau masyarakat. Keinginan seseorang untuk berbakti inilah yang membuat seseorang bekerja tanpa menghiraukan besarnya imbalannya tapi yang lebih penting lagi ialah hasil kerja yang menjadi prestasi kerjanya.

Sebagai salah satu perusahaan yang bergerak di bidang jasa keuangan, performa dan image sangatlah penting bagi BPR Arto Moro. Performa disini adalah performa perusahaan secara keseluruhan dan performa karyawan sebagai ujung tombak perusahaan. Untuk menimbulkan kepercayaan dan kenyamanan nasabah, karyawan BPR Arto Moro senantiasa dituntut untuk tampil percaya diri, prima, rapi, penuh antusiasme dan selalu siap sedia memberikan solusi ataupun pelayanan.

Karakter perusahaan yang mensaratkan ketersediaan karyawan dengan kualifikasi dan penampilan seperti tersebut, membuat karyawan BPR Arto Moro harus selalu tampil prima dan segar setiap harinya. Untuk bisa tampil prima dan segar tentu saja suasana batin harus berada dalam keadaan baik. Tanpa suasana batin yang baik, maka cerminan yang tampak dari luar adalah kelesuan dan ketiadaan semangat ataupun gairah. Dengan suasana batin yang baik, maka karyawan akan mampu mengkondisikan fisik dan hatinya untuk tampil prima, optimal, dan sesuai sehingga motivasi kerja selalu terjaga dalam level tinggi.

Dari visi dan misi serta dokumen Rencana Strategis Perusahaan untuk tahun 2020-2025, BPR Arto Moro menargetkan di tahun 2023 aset akan menjadi sebesar Rp 1 triliun dan posisi BPR Arto Moro akan menjadi BPR terbaik nomor 1 di kota Semarang. Untuk mewujudkan rencana besar tersebut, berbagai perbaikan sudah dilakukan oleh perusahaan, mulai dari penguatan infrastruktur, pembenahan system, dan pemantapan sumber daya manusia. Menarik untuk dilihat disini adalah apa saja upaya yang dilakukan oleh BPR Arto Moro dalam meningkatkan komitmen dan loyalitas kerja karyawanya sehingga target yang dicanangkan perusahaan tercapai

\section{Tujuan Penelitian}

1. Menganalisis pengaruh dukungan organisasi terhadap Employee engagement karyawan di BPR Arto Moro Semarang.

2. Menganalisis pengaruh budaya organisasi terhadap Employee engagement karyawan di BPR Arto Moro Semarang.

3. Menganalisis pengaruh dukungan organisasi terhadap loyalitas kerja karyawan di BPR Arto Moro Semarang.Menganalisis pengaruh budaya organisasi terhadap loyalitas kerja karyawan di BPR Arto Moro Semarang. 
4. Menganalisis pengaruh employee engagement terhadap loyalitas kerja karyawan di BPR Arto Moro Semarang.

\section{KAJIAN PUSTAKA (12 TNR)}

\section{Loyalitas Kerja}

Menurut Runtu (2014) Loyalitas tidak mungkin dianggap sebagai sesuatu yang terjadi dengan sendirinya ketika seorang karyawan bergabung dalam organisasi. Apabila organisasi menginginkan seorang karyawan yang loyal, organisasi harus mengupayakan agar karyawan menjadi bagian dari organisasi yang merupakan tingkatan lebih tinggi. Dengan demikian karyawan tersebut sungguh merasa bahwa "suka-duka" organisasi adalah "suka-duka"-nya juga. Oleh karena itu loyalitas mencakup kesediaan untuk tetap bertahan, memiliki produktivitas yang melampaui standard, memiliki perilaku altruis, serta adanya hubungan timbal balik di mana loyalitas karyawan harus diimbangi oleh loyalitas organisasi terhadap karyawan.Loyalitas tidak mungkin dianggap sebagai sesuatu yang terjadi dengansendirinya ketika seorang karyawan bergabung dalam organisasi. Karyawan yang memiliki loyalitas yang rendah diantaranya karena sifat karakternya (bawaan), kekecewaan karyawan, dan sikap atasan, serta perasaan negatif, seperti ingin meninggalkan organisasi, merasa bekerja di organisasi lain lebih menguntungkan, tidak merasakan manfaat, dan menyesali bergabung dengan organisasi. Adapun karakteristik karyawan yang menunjukkan loyalitas yang tinggi terhadap perusahaan, diantaranya adalah: a) bersedia bekerja melebihi kondisi biasa, b) merasa bangga atas prestasi yang dicapai perusahaan, c) merasa terinspirasi, d) bersedia mengorbankan kepentingan pribadi, dan e) merasa ada kesamaan nilai dengan perusahaan.

\section{Employee Engagement}

Komitmen terhadap kesuksesan pekerjaan sering disebut sebagai employee engagement. Employee engagement merupakan suatu istilah yang relatif baru dalam ilmu sumber daya manusia, dimana kata tersebut sering digunakan oleh lembaga konsultan yang khusus bergerak dalam bidang sumber daya manusia. Employee engagement merupakan gagasan dalam perilaku organisasi yang menjadi daya tarik dalam beberapa tahun terakhir. Daya tarik ini timbul karena employee engagement berpengaruh pada kinerja perusahaan secara keseluruhan. Hal ini telah didefinisikan oleh salah satu organisasi riset terkemuka sebagai hubungan emosional yang tinggi yang seorang karyawan rasakan terhadap organisasinya yang mempengaruhinya untuk mengerahkan usaha yang bebas dan lebih besar untuk pekerjaannya.(Risher, 2010).

\section{Budaya Organisasi}

Menurut Darojat (2015) Kata budaya (culture) berasal dari disiplin ilmu Antropologi; dengan tokohnya Killman, diartikan sebagai filsafah, ideologi, nilai - nilai, anggapan, keyakinan harapan, sikap, dan norma yang dimiliki bersama dan mengikat suatu masyarakat. Selanjutnya menurut Deal dan Kennedy (dalam Darojat, 2015) budaya adalah pola terintegrasi dari perilaku manusia termasuk pikiran, pembicaraan, tindakan, dan artifak serta tergantung pada kapasitas orang untuk menyimak, dan meneruskan pengetahuan kepada generasi penerus. Sedangkan pengertian dari 
organisasi menurut Ernawan (2011) ialah sesuatu yang abstrak, sulit dilihat tetapi bisa kita rasakan eksistensinya. Adapun pendapat lainnya yang dikemukakan oleh Robbins (dalam Yasrie, 2013) organisasi merupakan kesatuan sosial yang dikoordinasikan secara sadar, dengan sebuah batasan yang relatif dapat diindentifikasikan, secara terus menerus untuk mencapai tujuan. Maka dapat disimpulkan bahwa organisasi adalah suatu wadah yang di dalamnya terdapat sekumpulan orang yang bekerja sama untuk mencapai tujuan organisasi.

\section{Dukungan Organisasi}

Persepsi dukungan organisasi mengacu pada persepsi karyawan mengenai sejauh mana organisasi menilai kontribusi, memberi dukungan, dan peduli pada kesejahteraan mereka. Jika karyawan menganggap bahwa dukungan organisasi yang diterimanya tinggi, maka karyawan tersebut akan menyatukan keanggotaan sebagai anggota organisasi ke dalam identitas diri mereka dan kemudian mengembangkan hubungan dan persepsi yang lebih positif terhadap organisasi tersebut. Dengan menyatunya keanggotaan dalam organisasi dengan identitas karyawan, maka karyawan tersebut merasa menjadi bagian dari organisasi dan merasa bertanggung jawab untuk berkontribusi dan memberikan kinerja terbaiknya pada organisasi (Rhoades \& Eisenberger, 2002). Selanjutnya dikatakan bahwa persepsi terhadap dukungan organisasi juga dianggap sebagai sebuah keyakinan global yang dibentuk oleh tiap karyawan mengenai penilaian mereka terhadap kebijakan dan prosedur organisasi. Keyakinan ini dibentuk berdasarkan pada pengalaman mereka terhadap kebijakan dan prosedur organisasi, penerimaan sumber daya, interaksi dengan agen organisasinya (misalnya supervisor), dan persepsi mereka mengenai kepedulian organisasi terhadap kesejahteraan mereka.

\section{Hipotesis Penelitian}

H1 : Diduga dukungan organisasi mempunyai pengaruh terhadap employee engagement.

$\mathrm{H} 2$ : Diduga budaya organisasi mempunyai pengaruh terhadap employee engagement.

H3 : Diduga dukungan organisasi mempunyai pengaruh terhadap loyalitas kerja karyawan.

H4 : Diduga budaya organisasi mempunyai pengaruh terhadap loyalitas kerja karyawan.

H5 : Diduga employee engagement mempunyai pengaruh terhadap loyalitas kerja.

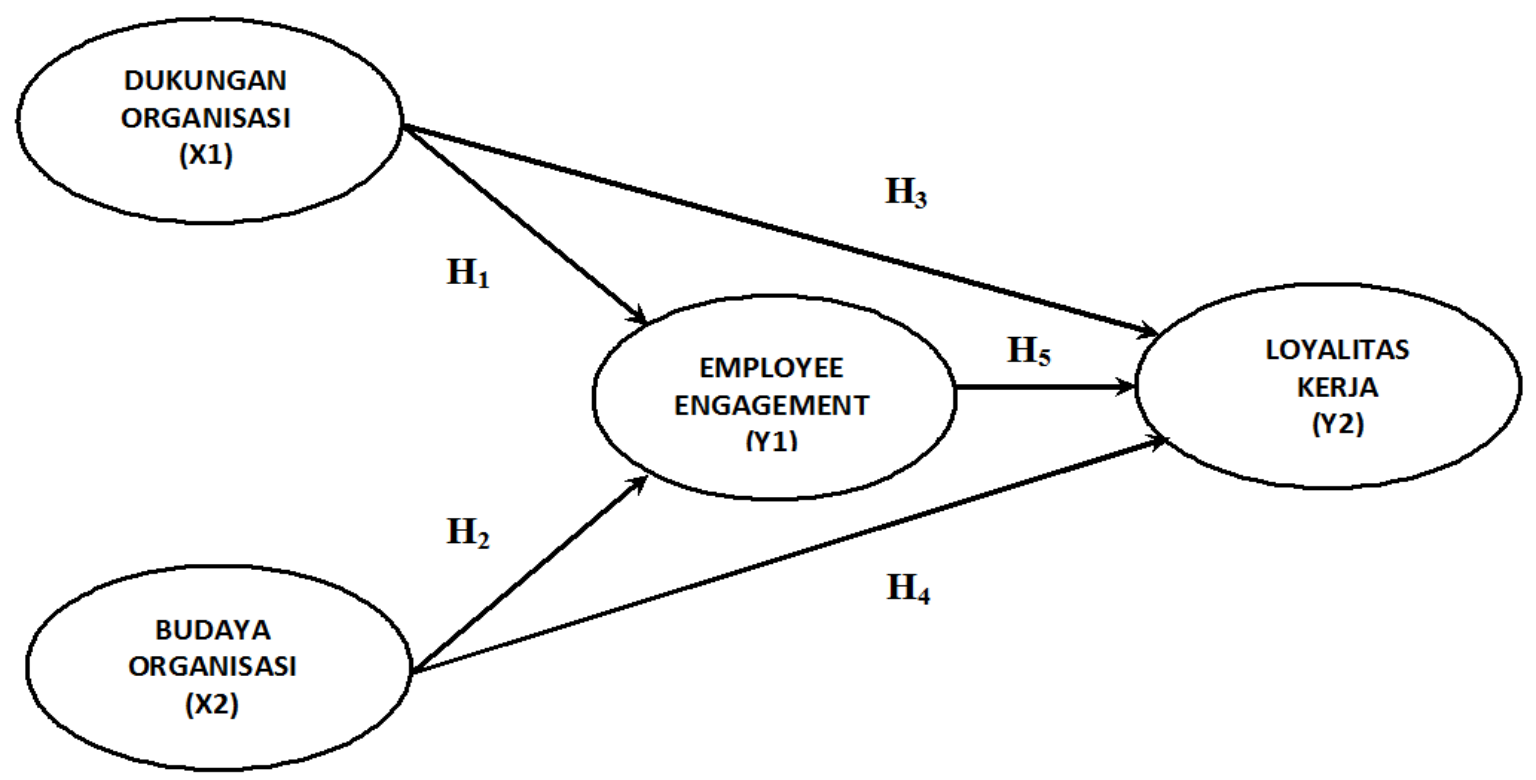




\section{METODE PENELITIAN}

Jenis penelitian ini adalah penelitian kuantitatif. Lokasi penelitian dilakukan di BPR Arto Moro Semarang yang beralamat di jalan Gajah Raya no. 155 Semarang. Jumlah sampel dalam penelitian ini 102 responden, menggunakan teknik sensus dimana seluruh karyawan 102 diambil sebagai sampel penelitian ini. Teknik analisis data menggunakan regresi linier berganda dan metode pengumpulan data yang digunakan adalah kuesioner.

\section{Metode Analisis}

\section{Uji Validitas}

Perhitungan validitas untuk mengukur sah atau valid tidaknya kuesioner Secara statistik, angka korelasi yang diperoleh harus dibandingkan antara $r$ hitung dengan $r$ tabel. Jika $r$ hitung $>r$ tabel maka indikator dinyatakan valid. Untuk mempermudah analisis data, uji validitas akan dilakukan dengan bantuan program SPSS 22. Jika r-hitung $\geq$ r-tabel, maka butir pertanyaan tersebut dikatakan valid. Jika r-hitung < r-tabel, maka butir pertanyaan tersebut dikatakan tidak valid. Nilai r-hitung diperoleh dari hasil pengolahan menggunakan komputer program SPSS 19. Sedangkan nilai r-tabel diperoleh dengan melihat tabel pembanding dengan taraf signifikansi 5\%.

Jenis penelitian ini adalah penelitian kuantitatif. Lokasi penelitian dilakukan di BPR Arto Moro Semarang yang beralamat di jalan Gajah Raya no.155 Semarang. Jumlah sampel dalam penelitian ini 102 responden, menggunakan teknik sensus dimana seluruh karyawan 102 diambil sebagai sampel penelitian ini. Teknik analisis data menggunakan regresi linier berganda dan metode pengumpulan data yang digunakan adalah kuesioner.

\section{Metode Analisis}

\section{Uji Validitas}

Perhitungan validitas untuk mengukur sah atau valid tidaknya kuesioner Secara statistik, angka korelasi yang diperoleh harus dibandingkan antara $r$ hitung dengan $r$ tabel. Jika $r$ hitung $>r$ tabel maka indikator dinyatakan valid. Untuk mempermudah analisis data, uji validitas akan dilakukan dengan bantuan program SPSS 22. Jika r-hitung $\geq$ r-tabel, maka butir pertanyaan tersebut dikatakan valid. Jika $r$-hitung $<$ r-tabel, maka butir pertanyaan tersebut dikatakan tidak valid. Nilai r-hitung diperoleh dari hasil pengolahan menggunakan komputer program SPSS 19. Sedangkan nilai r-tabel diperoleh dengan melihat tabel pembanding dengan taraf signifikansi $5 \%$.

\begin{tabular}{|c|c|r|r|c|}
\hline \multicolumn{1}{|c|}{ Variabel } & Indikator & $\begin{array}{c}\text { Korelasi } \\
\text { Pearson }\end{array}$ & Tabel R & Kesimpulan \\
\hline Dukungan Organisasi & X1.1 : Penghargaan Tugas & 0,736 & 0,194 & Valid \\
& X1.2: Peduli Keluhan Karyawan & 0,754 & 0,194 & Valid \\
& X1.3: Kesejahteraan Karyawan & 0,758 & 0,194 & Valid \\
& X1.4: Kepuasan Kerja Karyawan & 0,834 & 0,194 & Valid \\
& X1.5: Kebanggaan pada Karyawan & 0,748 & 0,194 & Valid \\
\hline Budaya Organisasi & X2.1: Ketaatan pada Pimpinan & 0,783 & 0,194 & Valid \\
& X2.2: Tanggungjawab Kerja & 0,734 & 0,194 & Valid \\
\hline
\end{tabular}




\begin{tabular}{|l|c|c|c|c|}
\hline & X2.3: Pembagian Tugas Jelas & 0,772 & 0,194 & Valid \\
& X2.4: Kerjasama Karyawan & 0,728 & 0,194 & Valid \\
& X2.5: Kedisiplinan Kerja & 0,827 & 0,194 & Valid \\
X2.6: Kualitas Kerja & 0,748 & 0,194 & Valid \\
& X2.7: Evaluasi Kerja & 0,749 & 0,194 & Valid \\
\hline \multirow{2}{*}{ Employee Engagement } & Y1.1: Memahami Pekerjaan & 0,753 & 0,194 & Valid \\
& Y1.2: Persiapan Kerja & 0,776 & 0,194 & Valid \\
& Y1.3: Prestasi Kerja & 0,735 & 0,194 & Valid \\
& Y1.4: Pengaruh Rekan Kerja & 0,765 & 0,194 & Valid \\
& Y1.5: Semangat Kerja & 0,696 & 0,194 & Valid \\
& Y1.6: Komitmen Rekan Kerja & 0,773 & 0,194 & Valid \\
\hline \multirow{2}{*}{ Loyalitas Kerja } & Y2.1: Keinginan Tetap Bertahan & 0,755 & 0,194 & Valid \\
& Y2.2: Bersedia Kerja Lembur & 0,715 & 0,194 & Valid \\
& Y2.3: Menjaga Rahasia Kantor & 0,756 & 0,194 & Valid \\
& Y2.4: Bangga sebagai Karyawan & 0,752 & 0,194 & Valid \\
& Y2.5: Mentaati Semua Peraturan & 0,706 & 0,194 & Valid \\
& Y2.6: Mendahulukan Kepentingan & 0,631 & 0,194 & Valid \\
\hline
\end{tabular}

\section{Uji Reliabilitas}

Reliabilitas adalah alat ukur untuk mengukur suatu kuesioner yang merupakan indikator dari suatu variabel. Suatu kuesioner dikatakan reliebel atau handal jika jawaban seseorang terhadap pertanyaan adalah konsisten atau stabil dari waktu ke waktu. Suatu data dikatakan reliabel adalah variabel memiliki nilai Cronbach Alpha $>0,6$ atau tidak reliabel apabila memiliki nilai Cronbach Alpha $<0,6$ (Ghozali, 2011).

\section{Uji Asumsi Klasik}

Untuk mengetahui apakah model regresi benar-benar menunjukan hubungan yang signifikan dan representatif, maka model tersebut harus memenuhi asumsi klasik regresi. Uji asumsi klasik yang digunakan adalah uji normalitas, multikolinealitas, autokorelasi, dan heteroskedastisitas.

\section{Uji Normalitas}

Uji normalitas digunakan untuk menguji apakah dalam model regresi, kedua variabel (bebas maupun terikat) mempunyai distribusi normal atau setidaknya mendekati normal. Analisis statistik digunakan mendeteksi normalitas dalam penelitian ini dilakukan dengan uji statistik. Test statistik sederhana yang dapat dilakukan berdasarkan p plot dan nilai Kolmogorov Smirnov dengan menggunakan fasilitas SPSS (Statistical Product Service Solution). Untuk mengetahui apakah data tersebut berdistribusi normal, maka dapat dilihat dengan Kolmogorov Smirnov Test. Adapun kriterianya adalah: Angka signifikansi (Sig) > 0,05 , maka data berdistribusi normal.

\section{Uji Multikolinieritas}

Uji multikolinieritas Yaitu untuk menguji apakah dalam model regresi ditemukan adanya kolerasi antar variabel bebas dan model yang baik seharusnya tidak terjadi multikolonieritas. Jika nilai tolerance $>0,1$ dan nilai VIF $<10$, maka dapat disimpulkan bahwa tidak ada multikolonieritas antar variable independen dalam model regresi. Jika nilai tolerance $<0,1$ dan VIF $>10$, maka dapat disimpulkan bahwa ada multikolonieritas antar variabel independen dalam model regresi. 


\section{Uji Heterokendastisitas}

Bertujuan menguji apakah dalam model regresi terjadi ketidaksamaan variance dari residual satu pengamatan ke pengamatan yang lain. Jika variance dari residual suatu pengamatan ke pengamatan yang lain tetap, maka disebut Homoskedastatitas dan jika berbeda disebut heteroskedastatitas. Model regresi yang baik jika tidak ditemukan Hetroskedositas. Menurut Ghozali (2011) dasar analisisinya adalah: uji heterokedastisitas menggunakan uji glejser menunjukan jika nilai probabilitas signifikasinya di atas tingkat kepercayaan 5\% jadi dapat disimpulkan model regresi tidak mengandung adanya heteroskedastisitas.

\section{Analisis Regresi Linier Berganda}

Analisis regresi linier berganda adalah hubungan secara linier antara dua atau lebih variabel independen $\left(\mathrm{X}_{1}, \mathrm{X}_{2}, \ldots . ., \mathrm{Xn}\right)$ dengan variabel $(\mathrm{Y})$. Analisis ini untuk mengetahui arah hubungan antara variabel independen dengan variabel dependen, apakah masing-masing variabel independen berhubungan positif atau negatif dan untuk memprediksi nilai dari variabel dependen apabila nilai variabel independen mengalami kenaikan atau penurunan. Data yang digunakan biasanya berskala interval atau rasio.

Persamaan regresi linier berganda sebagai berikut :

Persamaan 1 :

$\mathrm{Y} 1=\beta 1 \mathrm{X} 1+\beta 2 \mathrm{X} 2+\mathrm{e}$

Persamaan 2:

$\mathrm{Y} 2=\beta 3 \mathrm{X} 1+\beta 4 \mathrm{X} 2+\beta 5 \mathrm{Y} 1+\mathrm{e}$

Keterangan :

$\begin{array}{ll}\text { Y1 } & : \text { Employee Engagement } \\ \text { Y2 } & : \text { Loyalitas Kerja } \\ \mathrm{X} 1 & : \text { Dukungan Organisasi } \\ \mathrm{X} 2 & : \text { Budaya Organisasi } \\ \beta 1, \beta 2, \beta 3, \ldots & : \text { Koefisien Regresi } \\ \mathrm{e} & : \text { error }\end{array}$

\section{Uji Signifikasi (t)}

Uji ini bertujuan untuk mengetahui seberapa jauh pengaruh variabel bebas $\left(\mathrm{X}_{1}, \mathrm{X}_{2}, \ldots . ., \mathrm{Xn}\right)$ secara individual dalam menjelaskan variabel terikat (Y) (Tulandi Riry Anggia, 2015). Uji signifikasi mempunyai nilai signifikasi $\alpha=5 \%$. Kriteria penguji hipotesis dengan menggunakan uji t adalah :

- Jika t hitung $>\mathrm{t}$ tabel maka $\mathrm{H}_{0}$ ditolak, Ha diterima artinya ada pengaruh

- Jika $\mathrm{t}$ hitung $<\mathrm{t}$ tabel maka $\mathrm{H}_{0}$ diterima, Ha ditolak artinya tidak ada pengaruh

\section{Uji Determinasi $\left(\mathbf{R}^{2}\right)$}

Analisis ini digunakan untuk mengetahui hubungan antara dua atau lebih variabel independen $\left(\mathrm{X}_{1}, \mathrm{X}_{2}, \ldots .\right.$. , $\mathrm{Xn}$ ) terhadap variabel dependen $(\mathrm{Y})$ secara serentak. Koefisien ini menunjukkan seberapa besar hubungan yang terjadi antara variabel $\left(\mathrm{X}_{1}, \mathrm{X}_{2}, \ldots . ., \mathrm{Xn}\right)$ secara serentak terhadap terhadap variabel dependen (Y). Nilai $\mathrm{R}$ berkisar $0 \mathrm{~s} / \mathrm{d} 1$, dimana nilai semakin mendekati 1 berarti hubungan yang terjadi makin kuat. Sebaliknya nilai semakin mendekati 0 maka hubungan yang terjadi semakin lemah. 
Tabel 2. Uji Hipotesis Penelitian

\begin{tabular}{|c|r|r|r|c|}
\hline Hipotesa & & Koefisien Jalur & nilai-t & Hasil \\
\hline Dukungan Organisasi $\rightarrow$ Employee Engagement & H1 & 0,170 & 1,998 & Dukung \\
\hline Budaya Organisasi $\rightarrow$ Employee Engagement & H2 & 0,406 & 3,916 & Dukung \\
\hline Dukungan Organisasi $\rightarrow$ Loyalitas Kerja & H3 & 0,187 & 2,701 & Dukung \\
\hline Budaya Organisasi $\rightarrow$ Loyalitas Kerja & H4 & 0,378 & 3,777 & Dukung \\
\hline Employee Engagement $\rightarrow$ Loyalitas Kerja & H3 & 0,397 & 4,043 & Dukung \\
\hline
\end{tabular}

\section{Kesimpulan}

\section{KESIMPULAN DAN SARAN}

Penelitian mengenai pengaruh dukungan organisasi dan budaya organisasi terhadap employee engagement dan dampaknya pada loyalitas kerja karyawan di BPR Arto Moro Semarang dapat diambil beberapa kesimpulan berikut ini :

1. Variabel dukungan organisasi terhadap employee engagement mempunyai koefisien regresi sebesar 0,170, t hitung 1,998 > t tabel 1,66008 dan tingkat signifikasi 0,048< dari $\alpha$ yaitu 0,05 , sehingga $\mathrm{H}_{0}$ ditolak dan Ha diterima, berarti dukungan organisasi berpengaruh positif dan signifikan terhadap employee engagement.

2. Variabel budaya organisasi terhadap employee engagement mempunyai koefisien regresi sebesar 0,406, t hitung 3,916 > t tabel 1,66008 dan tingkat signifikasi 0,001 < $\alpha$ yaitu 0,05 , sehingga $\mathrm{H}_{0}$ ditolak dan $\mathrm{Ha}$ diterima berarti budaya organisasi berpengaruh positif dan signifikan terhadap employee engagement.

3. Variabel dukungan organisasi terhadap loyalitas kerja terhadap loyalitas kerja mempunyai koefisien regresi sebesar 0,187, t hitung 2,701 > t tabel 1,66008 dan tingkat signifikasi $0,006<$ dari $\alpha$ yaitu 0,05 , sehingga $\mathrm{H}_{0}$ ditolak dan Ha diterima, berarti dukungan organisasi berpengaruh positif dan signifikan terhadap loyalitas kerja karyawan.

4. Variabel budaya organisasi terhadap loyalitas kerja mempunyai koefisien regresi sebesar 0,378, t hitung 3,777 > t tabel 1,66008 dan tingkat signifikasi 0,003 $<$ dari $\alpha$ yaitu 0,05 , sehingga $\mathrm{H}_{0}$ ditolak dan $\mathrm{Ha}$ diterima, berarti budaya organisasi berpengaruh positif dan signifikan terhadap loyalitas kerja karyawan.

5. Variabel employee engagement terhadap loyalitas kerja mempunyai koefisien regresi sebesar 0,397, thitung 4,043 > t tabel 1,66008 dan tingkat signifikasi $0,001<$ dari $\alpha$ yaitu 0,05 , sehingga $\mathrm{H}_{0}$ ditolak dan $\mathrm{Ha}$ diterima, berarti employee engagement berpengaruh positif dan signifikan terhadap loyalitas kerja karyawan.

\section{Saran}

Berdasarkan deskriptif hasil penelitian variabel dukungan organisasi dan budaya organisasi terhadap employee engagement dan dampaknya pada loyalitas kerja karyawan di BPR Arto Moro Semarang, maka saran dari hasil penelitian ini dapat dikembangkan berdasarkan hasil tersebut. Saran yang dapat diberikan sebagai berikut : 
1. Untuk variabel dukungan organisasi dimana pengelola BPR Arto Moro Semarang dapat menciptakan hubungan yang harmonis antara pimpinan dengan pimpinan, pimpinan dengan bawahan dan bawahan dengan bawahan untuk terus dilakukan evaluasi dan monitoring berkaitan dengan tugas dan tanggungjawab yang jelas antara keduanya demi kelancaran suatu kegiatan

2. Untuk variabel budaya organisasi, kedisiplinan dan ketaatan pada peraturan kerja baik untuk perorangan maupun unit kerja harus tetap dijaga perilaku adil dan sama agar tidak menimbulkan keluhan pada karyawan lain ataupun kecemburuan unit kerja yang lain, karena kedisiplinan adalah kunci keberhasilan dalam pencapaian suatu prestasi.

3. Untuk variabel employee engagement pengelola BPR Arto Moro Semarang yakin bahwa karyawan mempunyai integritas dan berguna bagi perusahaan dalam pencapaian tujuan, visi dan misinya, demikian pula karyawan juga harus percaya bahwa perusahaan bisa menjadikannya sebagai pribadi yang berkembang baik dari segi pengetahuan, kemampuan, penghasilan untuk kesejahteraan yang lebih meningkat.

4. Untuk variabel loyalitas kerja, perusahaan berusaha seoptimal mungkin untuk memenuhi semua kebutuhan dan keinginan karyawan, maka secara otomatis dengan penuh kesadaran mereka akan meningkatkan tingkat loyalitas kerja dalam dirinya

5. Hasil uji R2 menunjukkan masih ada variabel lain yang harus diteliti lagi, artinya bagi peneliti selanjutnya dapat mengembangkan penelitian ini dengan menambahkan variabel yang lain atau metode yang lain, sehingga informasi yang diperoleh lebih bervariasi dari sebelumnya.

\section{DAFTAR PUSTAKA}

Agus Tunggal Saputra, I Wayan Bagia, Ni Nyoman Yulianthini, Pengaruh Kepuasan Kerja dan Loyalitas Kerja Karyawan Terhadap Kinerja Karyawan, e-Journal Bisma Universitas Pendidikan Ganesha Jurusan Manajemen (Volume 4 Tahun 2016).

Deal, T. E., \& Kennedy, A. A., (2012), Corporate culture: The rites and rituals of corporate life. Massachusetts: Addison-Wesley

Ernawan, Erni R. 2011. Organizational Culture: Budaya Organisasi dalam Perspektif Ekonomi dan Bisnis. Cetakan Kesatu. Alfabeta. Bandung.

Ferdinand, Augusty. 2000. Structural Equation Modeling dalam Penelitian Manajemen. BP Universitas Diponegoro. Semarang.

Ferdinand, Augusty. 2011, Metode Penelitian Manajemen Pedoman Penelitian untuk Penulisan Skripsi, Tesis, dan Disertasi Ilmu Manajemen, Edisi 3, AGF Books, Fakultas Ekonomika dan Bisnis Universitas Diponegoro, Semarang.

Gallup. (2004). Study Engaged Employees Inspire Company Innovation. Gallup Management Journal.

Ghozali, Imam. 2011, Aplikasi Analisis Multivariate dengan Program IBM SPSS 19. Semarang : Badan Penerbit Universitas Diponegoro

Gouzali Saydam, (2000), Manajemen Sumber Daya Manusia (Human Resource) Suatu Pendekatan Mikro, Djanbatan, Jakarta.

Hadari Nawawi, (2005), Manajemen Sumber Daya Manusia Untuk Bisnis Yang Kompetitif, Cetakan Ke-4, Gajah Mada Univercity Press, Yogyakarta.

Hasibuan, S.P Malayu (2005). Manajemen Sumber Daya Manusia. Edisi Revisi. Jakarta : Bumi Aksara.

Kadarwati. 2003, Manajemen Organisasi, Gramedia Asri Media. Jakarta. 
Kahn, W. A. (1990). Psychological Conditions Of Personal Engagement And Disengagement At Work. Academy of management journal Vol. 33, No. 4 : hal. 692-724.

Meglino, B. M., Ravlin, E. C.,\& Adkins, C. L. (1989). A work values approach to corporate culture: a field test of the value congruence process and its 100 relationship to individual outcomes. Journal of Applied Psychology,74(3),424-432.

Nusatria, Sandi. 2012. "Employee Engagement : Anteseden dan Konsekuensi Studi pada Unit CS PT. Telkom Indonesia Semarang". Jurnal Universitas Indonesia. pp 1-68.

Rhoades, L., Eisenberger, R. \& Armeli, S. (2001). Affective Commitment to the Organization: The Contribution of Perceived Organizational Support. Journal of Applied Psychology, 86(5), 825-836.

Rhoades, L. \& Eisenberger, R. (2002). Perceived organizational support: A review of literature. Journal of Applied Psychology Vol. 87.

Risher (2010). Don't Overlook Frontline Supervisors. Public Manager.

Robbins. Stephen. P., Coulter. Mary., (2012), Management. Eleventh Edition, Jakarta: England.

Runtu, Julius. (2014). Indikator loyalitas karyawan. (www.juliusruntu. blogspot.com/2014/ 02/indikator-loyalitas-karyawan-bahan.html?m=1), diakses pada 20 Januari 2016.

Saragih, Susanti dan Meily Margaretha. 2013. "Anteseden dan Konsekuensi Employee Engagement: Studi pada Industri Perbankan”. Seminar Nasional dan Call for Paper, Universitas Kristen Maranatha, Bandung, pp 1-21.

Soedjono S. 2005. Pengaruh Budaya Organisasi Terhadap Kinerja Organisasi dan Kepuasan Kerja Karyawan pada Terminal Penumpang Umum di Surabaya. Jurnal Manajemen dan Kewirausahaan Vol. 7, No. 1.

Steers, R.M and Porter, R. W (1983). Motivation and Work Behavior. New York: Mc Graw Hill. Sugiyono. 2009. Metode Penelitian Kuantitatif dan Kualitatif. Bandung: CV. Alfabeta.

Tubagus A.Darojat. 2015.PentingnyaBudaya Kerja Tinggi dan Budaya Kerja Kuat.PT Refika Aditama, Bandung.

Veithzal Rivai. 2004. Manajemen Sumber Daya Manusia Untuk Perusahaan : Dari Teori Ke Praktik. PT. Raja Grafindo Persada, Jakarta.

Wahyuningsih, Putri. 2012. "Pengaruh Letak Kendali Diri, Jabatan Organisasi, Konflik Peran Dan Budaya Organisasi Terhadap Kepuasan Kerja". Jurnal, STIE Perbanas Surabaya, Surabaya.

Werther, William B. dan Keith Davis, 1996. Manajemen Personalia dan Sumber Daya Manusia, Erlangga, Jakarta.

Wexley, Kenneth. and Gary Yukl. (1977). Perilaku Organisasi dan Psikologi Personalia. Jakarta: Rineka Cipta.

Yasrie, Arfie. (2013). Pengaruh Budaya Organisasi Terhadap Kinerja Pegawai. Dinas Pendidikan Provinsi Kalimantan Selatan. Socioscientia.

Zumrah. 2013. The Effect of Perceived Organizational Support and Job Satisfaction on Transfer 